\title{
Adherence to treatment and related factors among patients with chronic conditions in primary care: a cross-sectional study
}

Cesar I. Fernandez-Lazaro ${ }^{1,2^{*}}$ (D), Juan M. García-González ${ }^{3}$, David P. Adams ${ }^{4}$, Diego Fernandez-Lazaro ${ }^{5}$, Juan Mielgo-Ayuso ${ }^{6}$, Alberto Caballero-Garcia ${ }^{7}$, Francisca Moreno Racionero ${ }^{8}$, Alfredo Córdova $^{6}$ and Jose A. Miron-Canelo ${ }^{1}$

\begin{abstract}
Background: Adherence to treatment, a public health issue, is of particular importance in chronic disease therapies. Primary care practices offer ideal venues for the effective care and management of these conditions. The aim of this study is to assess adherence to treatment and related-factors among patients with chronic conditions in primary care settings.

Methods: A cross-sectional study was conducted among 299 adult patients with $\geq 1$ chronic condition(s) and prescribed medication in primary healthcare centers of Spain. The Morisky-Green-Levine questionnaire was used to assess medication adherence via face-to-face interviews. Crude and adjusted multivariable logistic regression models were used to analyze factors associated with adherence using the Multidimensional Model proposed by the World Health Organization — social and economic, healthcare team and system-related, condition-related, therapy-related, and patient-related factors.
\end{abstract}

Results: The proportion of adherent patients to treatment was 55.5\%. Older age (adjusted odds ratio 1.31 per 10year increment, $95 \% \mathrm{Cl} 1.01-1.70)$, lower number of pharmacies used for medication refills $(0.65,95 \% \mathrm{Cl} 0.47-$ 0.90), having received complete treatment information (3.89,95\% Cl 2.09-7.21), having adequate knowledge about medication regimen $(4.17,95 \% \mathrm{Cl} 2.23-7.80)$, and self-perception of a good quality of life $(2.17,95 \% \mathrm{Cl}$ 1.18-4.02) were independent factors associated with adherence.

Conclusions: Adherence to treatment for chronic conditions remained low in primary care. Optimal achievement of appropriate levels of adherence through tailored multifaceted interventions will require attention to the multidimensional factors found in this study, particularly those related to patients' education and their information needs.

Keywords: Treatment adherence, Medication adherence, Patient adherence, Patient education, Chronic conditions, Multidimensional factors, WHO multidimensional framework, Primary care

\footnotetext{
* Correspondence: fernandezlazaro@usal.es

'Department of Biomedical and Diagnostic Sciences, School of Medicine, University of Salamanca, Calle Alfonso X el Sabio s/n, 37007 Salamanca, Spain ${ }^{2}$ Department of Preventive Medicine and Public Health, School of Medicine, IDISNA, University of Navarra, Pamplona, Spain

Full list of author information is available at the end of the article
}

(c) The Author(s). 2019 Open Access This article is distributed under the terms of the Creative Commons Attribution 4.0 International License (http://creativecommons.org/licenses/by/4.0/), which permits unrestricted use, distribution, and reproduction in any medium, provided you give appropriate credit to the original author(s) and the source, provide a link to the Creative Commons license, and indicate if changes were made. The Creative Commons Public Domain Dedication waiver (http://creativecommons.org/publicdomain/zero/1.0/) applies to the data made available in this article, unless otherwise stated. 


\section{Background}

The increase in life expectancy and the aging of the world population have been paralleled by an alarming growth in the global burden of chronic conditions [1]. Chronic diseases are generally considered physical or mental conditions that last more than a year and require ongoing care. They compromise the individuals' physical and social function, the health-related quality of life, and the economic sustainability of healthcare systems $[2,3]$. Their global prevalence has reached such unprecedented levels in many populations that chronic diseases currently represent a public health concern. Roughly a quarter of the European population suffers from at least one chronic condition, and an estimated 50 million people suffer from multimorbidity [4], the co-occurrence of two or more chronic diseases [5]. In the United States, chronic conditions affect $60 \%$ of American adults, and four in ten suffer from multimorbidity [6].

For people with chronic diseases, management of their conditions is fundamental to minimize their impact, improve health outcomes, prevent further disability, and reduce healthcare costs $[7,8]$. Adherence to treatment, the extent to which patients are able to follow the agreed recommendations for prescribed treatments with healthcare provider, is a key component of chronic disease management. Only half of patients with chronic conditions, however, take their medications as prescribed, making medication adherence improvement a priority of the public health agenda [9]. According to the World Health Organization (WHO), a series of factors, rather than a single one, determine patients' ability to follow treatment recommendations correctly. These factors interact and potentiate each other's influence in a framework determined by five dimensions - the social and economic, health-care team and system-related, condition-related, therapy-related, and patient-related [9].

Several attempts have been made in recent years to determine the most influential factors of adherence. Most research has focused on a single-dimension, usually patient-related factors [10] and have not taken into account the WHO framework. Other studies have focused on a single-disease, such as diabetes [11], coronary heart disease [12], and asthma [13], or on a particular drug therapy [14], an approach which limits the utility of the findings to the condition under study. To identify facilitators of adherence among chronic-disease patients, it is necessary to consider more than a single chronic condition and account for interaction of factors in a more multi-dimensional approach.

Spain has one of the highest prevalence of multimorbidity $[4,15,16]$ in Europe. Present demographic trends suggest its population will have the longest life expectancy in the world by 2040 [17]. Nonetheless, no studies have used a multi-dimensional approach to evaluate factors associated with medication adherence in primary care settings, venues that provide most of the care and management of chronic conditions [18-20]. Moreover, some authors have also emphasized the need to develop studies in the context of primary care to better assess medication adherence, as these places offer more accurate results and minimize selection bias [21]. Thus we aim to use the WHO conceptual framework to evaluate adherence and related factors among chronic-disease patients in these settings. Their assessments can guide interventions that will reduce healthcare costs and improve patients' health-related quality of life.

\section{Methods}

\section{Study design and settings}

A cross-sectional study was conducted in two primary healthcare centers between August 2016 and March 2017 in Soria, an urban city of 39,000 inhabitants located in the autonomous community of Castile and Leon, Spain. The Spanish National Health System (SNHS) provides universal health coverage to all Spanish citizens and foreign nationals and has two levels of care: Primary Health Care and Specialist Care.

Primary Health Care is distributed in health areas that provide basic health care services through one or more healthcare centers. All centers operate strive to follow the same principles to maximize healthcare accessibility and equity within the country. Healthcare centers in Spain offer services free of charge at the point of delivery such as consultations, health education, laboratory tests, physical therapy, and radiographic exams [22]. Currently, the facilities of the study are the main healthcare centers of the Health Area of Soria and provide healthcare services to the urban population of the city, one of the 52 Spanish provincial capitals.

\section{Population and sampling}

The sample population of the study was calculated based on the number of patients that attended the clinics and an estimated prevalence of chronic conditions among primary care population of $70 \%$ [16]. We accepted an expected proportion of the participants not adhering to prescribed medications of $75 \%$ [23, 24], keeping a 95\% confidence level, a 5\% tolerated error level, and a design effect of 1 . Taking into account a possible refusal rate of $20 \%$, the final sample size was calculated to be 344 patients.

The investigators screened potential candidates for participation at each center. After candidates' screening, research assistants randomly approached potential participants presenting at the centers for follow-up consultations, confirmed their eligibility, and invited them to participate in the study. Patients aged 18 years or older who suffered from one or more chronic condition(s) and 
had been prescribed medication for more than a year of treatment were considered eligible for inclusion in the study. Individuals with cognitive impairment or mental conditions that prevented them from responding appropriately, and those who declined to participate, were excluded from the study. A total of 23 health problems were defined as chronic conditions in the study (Additional file 1: Table S1). These conditions were selected because they are typically treated with prescribed medications and commonly occur in primary care settings.

\section{Data collection}

A questionnaire, previously designed by an expert group in medication adherence, was used to obtain information about patients' socio-demographic characteristics and factors related to adherence. Prior to its implementation, investigators piloted the survey on 30 subjects to ensure that it was easily understood, well-defined, and accurately addressed the goals of the study.

Data collection took place in a clinic consultation room after participants' appointment with their healthcare providers. Face-to-face, semi-structured interviews, were conducted by a pharmacist with extensive experience in adherence surveys. Each interviewer-patient session lasted between 20 and 30 minutes. Participation in the study was voluntary and all the subjects received a detailed explanation about the goals, objectives, methods, and purpose of the study. Patients, whose responses were coded to protect their confidentiality, were also informed they could withdraw from the study at any time without penalty.

The Ethics Committee of the Hospital Complex of Soria approved this study. All participants provided written informed consent to take part in the study.

\section{Measurement of exposure and covariates}

Self-reported adherence was determined using the Spanish validated version [25] of the four-item Morisky-Green-Levine Medication Assessment Questionnaire [26]. This method is simple, easy to implement, and has the ability to identify reasons underlying the medication adherence behavior. Furthermore, it has been widely used in numerous studies and clinical settings. The questionnaire consists of 4 yes/no questions: (i) Do you ever forget to take your medicine? (ii) Are you careless at times about taking your medicine? (iii) When you feel better, do you sometimes stop taking your medicine? and (iv) If you feel worse when you take the medicine, do you stop taking it? Each "yes" response received a score of "1", and each "no" response received a score of "0". Patients' overall medication adherence was categorized as follows: $\geq 3$ score $=$ low adherence; $1-2$ score $=$ medium adherence; and 0 score $=$ high adherence .

The following factors were considered for their possible association with medication adherence using the WHO multidimensional framework [9]:

\section{Social and Economic Factors}

Gender, age, immigration status (born in Spain vs. immigrated to Spain), household income (tertiles), living status (living alone vs. living with someone), and highest level of education (primary school or lower, secondary school, and university or higher) were included as social economic factors.

\section{Healthcare Team and System-Related Factors}

Information about patients' frequency of follow-up care for chronic diseases (monthly or more frequently, quarterly, and biannually or less frequently) and the number of pharmacies used for medication refills were considered. Additionally, patient-provider communication, perceived quality of healthcare delivery, and level of treatment information received were evaluated on a 5-point Likert scale: from "1" meaning very poor to " 5 " meaning very good. Scores above " 3 " were used to categorize respondents as having good communication with provider, perceiving good quality of healthcare delivery, and receiving complete treatment information for each item respectively.

\section{Condition-Related Factors}

Data about condition-related factors included the number of chronic conditions, adjusted morbidity group (AMG) based on the Clinical Risk Group classification [27], and lifestyle behavior such as alcohol consumption, tobacco smoking use, and levels of physical activity. The AMG is a new multi-morbidity risk adjustment measure of disease severity, number of diseases, healthcare services utilization, and difficulties associated with access to resources. This measure has been adapted to the Spanish Health System and has been used by the Castile and Leon Healthcare Services since 2013 to manage patients with chronic conditions [28].

Claim-based diagnoses were used to assign subjects to a mutually exclusive, hierarchically ranked risk, group burden of comorbid diseases: AMG1 (single minor chronic condition), AMG2 (multimorbidity with stable chronic conditions), and AMG3 (complex multimorbidity with severe chronic conditions). Regarding lifestyle, participants self-reported their frequency of alcohol consumption (daily drinker, occasional drinker, and non-drinker), tobacco smoking (smoker, ex-smoker, and nonsmoker), and physical activity during leisure time (active vs. non-active) according to the WHO recommendations [29]. 
Table 1 Social and Economic-, Healthcare Team and System-, and Condition-Related Factors of the Participants of the Study according to their Self-Reported Measure of Medication Adherence, $n=299$

\begin{tabular}{|c|c|c|c|c|c|c|}
\hline \multirow[t]{2}{*}{ Factors } & \multirow{2}{*}{$\begin{array}{l}\text { Total n (\%) } \\
n=299\end{array}$} & \multirow{2}{*}{$\begin{array}{l}\text { Adherent } n(\%) \\
n=166\end{array}$} & \multirow{2}{*}{$\begin{array}{l}\text { Poor Adherent } \mathrm{n}(\%) \\
n=133\end{array}$} & \multicolumn{3}{|c|}{ Bivariate Analyses } \\
\hline & & & & Crude OR & $95 \% \mathrm{Cl}$ & $p$-value \\
\hline \multicolumn{7}{|l|}{ Social and Economic } \\
\hline \multicolumn{7}{|l|}{ Gender } \\
\hline Male & $154(51.5)$ & $90(54.2)$ & $64(48.1)$ & Ref. & Ref. & \\
\hline Female & $145(48.5)$ & $76(45.8)$ & $69(51.9)$ & 0.78 & (0.50 to 1.24$)$ & 0.295 \\
\hline Age, mean $\pm S D$ & $65.79 \pm 13.7$ & $68.96 \pm 12.8$ & $61.83 \pm 13.9$ & 1.49 & (1.24 to 1.78$)$ & $<0.001$ \\
\hline \multicolumn{7}{|l|}{ Immigration Status } \\
\hline Born in Spain & $251(83.9)$ & $156(94.0)$ & $95(71.4)$ & Ref. & Ref. & \\
\hline Immigrated to Spain & $48(16.1)$ & $10(6.0)$ & $38(28.6)$ & 0.160 & (0.08 to 0.34 ) & $<0.001$ \\
\hline \multicolumn{7}{|l|}{ Household Income } \\
\hline 1st Tertile (lowest income) & $100(33.44)$ & $52(31.33)$ & $48(36.09)$ & Ref. & Ref. & \\
\hline 2nd Tertile & $100(33.44)$ & $62(37.35)$ & $38(28.57)$ & 1.51 & (0.86 to 2.65$)$ & 0.154 \\
\hline 3er Tertile (highest income) & $99(33.11)$ & $52(31.33)$ & $47(35.34)$ & 1.02 & (0.59 to 1.78 ) & 0.941 \\
\hline \multicolumn{7}{|l|}{ Living Status } \\
\hline Living alone & $63(21.1)$ & $28(16.9)$ & $35(26.3)$ & Ref. & Ref. & \\
\hline Living with someone & $236(78.9)$ & $138(83.1)$ & $98(73.7)$ & 1.69 & (1.01 to 3.08$)$ & 0.048 \\
\hline \multicolumn{7}{|l|}{ Education } \\
\hline Primary school or lower & $176(58.9)$ & $98(59.0)$ & 78 (58.7) & Ref. & Ref. & \\
\hline Secondary school & $88(29.4)$ & $51(30.7)$ & $37(27.8)$ & 1.10 & (0.65 to 1.84$)$ & 0.726 \\
\hline University or higher & $35(11.7)$ & $17(10.2)$ & $18(13.5)$ & 0.75 & (0.36 to 1.55$)$ & 0.441 \\
\hline \multicolumn{7}{|l|}{ Healthcare Team and System-Related } \\
\hline \multicolumn{7}{|l|}{ Frequency of Follow-up Care } \\
\hline Monthly or more frequently & $152(50.8)$ & $81(48.8)$ & $71(53.4)$ & Ref. & Ref. & \\
\hline Quarterly & $117(39.1)$ & $64(38.6)$ & $53(39.8)$ & 1.06 & (0.65 to 1.72$)$ & 0.818 \\
\hline Biannually or less frequently & $30(10.0)$ & $21(12.7)$ & $9(6.8)$ & 2.05 & (0.88 to 4.75$)$ & 0.096 \\
\hline Number of Pharmacies Used for Refills, mean $\pm S D$ & $1.64 \pm 1.0$ & $1.35 \pm 0.8$ & $2.00 \pm 1.2$ & 0.51 & (0.40 to 0.66$)$ & $<0.001$ \\
\hline \multicolumn{7}{|l|}{ Patient-provider Communication } \\
\hline Not having good communication & $24(8.0)$ & $9(5.4)$ & $15(11.3)$ & Ref. & Ref. & \\
\hline Having good communication & $275(92.0)$ & $157(94.6)$ & $118(88.7)$ & 2.22 & (1.03 to 6.11$)$ & 0.070 \\
\hline \multicolumn{7}{|l|}{ Quality of Healthcare Delivery } \\
\hline Not perceiving good quality of care & $13(4.3)$ & $5(3.0)$ & $8(6.0)$ & Ref. & Ref. & \\
\hline Perceiving good quality of care & $286(95.7)$ & $161(97.0)$ & $125(94.0)$ & 2.06 & (0.66 to 6.45$)$ & 0.214 \\
\hline \multicolumn{7}{|l|}{ Treatment Information Received } \\
\hline Not receiving complete information & $161(53.8)$ & $60(36.1)$ & $101(75.9)$ & Ref. & Ref. & \\
\hline Receiving complete information & $138(46.2)$ & $106(63.9)$ & $32(24.1)$ & 5.58 & (3.35 to 9.27 ) & $<0.001$ \\
\hline \multicolumn{7}{|l|}{ Condition-Related } \\
\hline Number of Chronic Conditions, mean \pm SD & $2.90 \pm 1.5$ & $3.08 \pm 1.6$ & $2.68 \pm 1.5$ & 1.19 & (1.02 to 1.39$)$ & 0.027 \\
\hline \multicolumn{7}{|l|}{ Adjusted Morbidity Group } \\
\hline AMG1 & $62(20.7)$ & $29(17.5)$ & $33(24.8)$ & Ref. & Ref. & \\
\hline AMG2 & $163(54.5)$ & 89 (53.6) & $74(55.6)$ & 1.37 & (0.76 to 2.46$)$ & 0.294 \\
\hline AMG3 & $74(24.8)$ & $48(28.9)$ & $26(19.5)$ & 2.10 & (1.05 to 4.19$)$ & 0.035 \\
\hline \multicolumn{7}{|l|}{ Alcohol Consumption } \\
\hline Daily drinker & $59(19.7)$ & $30(18.1)$ & $29(21.8)$ & Ref. & Ref. & \\
\hline
\end{tabular}


Table 1 Social and Economic-, Healthcare Team and System-, and Condition-Related Factors of the Participants of the Study according to their Self-Reported Measure of Medication Adherence, $n=299$ (Continued)

\begin{tabular}{|c|c|c|c|c|c|c|}
\hline \multirow[t]{2}{*}{ Factors } & \multirow{2}{*}{$\begin{array}{l}\text { Total n (\%) } \\
n=299\end{array}$} & \multirow{2}{*}{$\begin{array}{l}\text { Adherent } \mathrm{n}(\%) \\
n=166\end{array}$} & \multirow{2}{*}{$\begin{array}{l}\text { Poor Adherent } n(\%) \\
n=133\end{array}$} & \multicolumn{3}{|c|}{ Bivariate Analyses } \\
\hline & & & & Crude OR & $95 \% \mathrm{Cl}$ & $p$-value \\
\hline Occasional drinker & $101(33.8)$ & $51(30.7)$ & $50(37.6)$ & 0.99 & (0.52 to 1.87$)$ & 0.966 \\
\hline Non-drinker & $139(46.5)$ & $85(51.2)$ & $54(40.6)$ & 1.52 & (0.82 to 2.81$)$ & 0.824 \\
\hline \multicolumn{7}{|l|}{ Tobacco Smoking } \\
\hline Smoker & 49 (16.4) & $30(18.1)$ & $19(14.3)$ & Ref. & Ref. & \\
\hline Ex-smoker & $98(32.8)$ & $56(33.7)$ & $42(31.6)$ & 0.84 & (0.42 to 1.70$)$ & 0.636 \\
\hline Non-smoker & $152(50.8)$ & $80(48.2)$ & $72(54.1)$ & 0.70 & (0.37 to 1.36$)$ & 0.294 \\
\hline \multicolumn{7}{|l|}{ Physical Activity } \\
\hline Non-active & $128(42.8)$ & 64 (38.6) & $64(48.1)$ & Ref. & Ref. & \\
\hline Active & $171(57.2)$ & $102(61.4)$ & $69(51.9)$ & 0.68 & (0.43 to 1.07 ) & 0.097 \\
\hline
\end{tabular}

Abbreviations: $\mathrm{Cl}$, confidence interval; $O R$, odds ratio; $S D$, standard deviation; Ref., reference

Bold values are statistically significant at $p$-values $\leq 0.05$

\section{Therapy-Related Factors}

The number of prescriptions, pills, and use of medication by injections (use vs. non-use injections), and by inhalers (use vs. non-use inhalers) included in the treatment of each participant were considered as therapy-related factors. Moreover, patients reported on a 5-point Likert scale the degree to which treatment interfered with their activities of daily living with "1" meaning not any interference to " 5 " meaning very much interference. Scores above " 3 " were used to categorize treatment respondents viewed as interfering with activities of daily living.

\section{Patient-Related Factors}

Information collected about patient-related factors reflected in participants' functional independency of activities of daily living evaluated using the Barthel Index: independent, slightly dependent, moderately dependent, severely dependent, and totally dependent [30]; the use of aids to remember medication-dosing schedules (no reminders, alarms/phones/pillboxes, and association of medication with daily routines); knowledge of medication regimen, i.e., specific amount, number, and frequency of doses (adequate vs. inadequate knowledge); and whether patients perceived overmedication in their treatment (perception vs. noperception of overmedication). Individuals also reported their self-perceived quality of life on a 5-point Likert scale with " 1 " meaning very poor to " 5 " meaning very good. Scores above "3" were used to categorize respondents as having good quality of life.

\section{Data management and statistical analysis}

For statistical analyses participants were categorized according to their responses of the Morisky-Green-Levine questionnaire into an "adherent group" (questionnaire's score $=0 /$ high adherence) and a "poor-adherent group" (questionnaire's score $\geq 1 /$ medium and low adherence). Descriptive statistics included means and standard deviations (SD) for quantitative variables and percentages for categorical variables. We performed crude and adjusted multivariate logistic regression to evaluate factors associated with medication adherence. Covariates were included in the multivariate logistic regression model based on the crude association with adherence ( $p$-value $\leq 0.05$ ). These variables were age, immigration status, living status, number of pharmacies used for medication refills, treatment information received, number of chronic conditions, adjusted morbidity group, interference of therapy on daily life activities, medication dosing reminders, patients' knowledge about medication regimen, and self-perceived quality of life. Sensitivity analyses were additionally performed to confirm the relationship between risk factors and adherence. No issues of multicollinearity were observed. These analyses were performed using Stata software, version 14.0 (StataCorp LP, College Station, TX) with a two-tailed level of statistical significance set at $p$-value $\leq 0.05$.

\section{Results \\ Sample characteristics}

Among the 344 eligible patients randomly invited to participate in the study, $41(11.9 \%)$ refused to participate and 4 (1.2\%) withdrew during the interview process. The characteristics of the excluded subjects were similar to those of the overall group. The mean age of participants was $65.8 \pm 13.7$ years; most were male $(51.5 \%)$ and born in Spain (83.9\%). Nearly half had at least graduated from secondary school (41.1\%). Participants had a mean number of $3.9 \pm 2.2$ prescriptions in their treatment and suffered an average of $2.9 \pm 1.5$ chronic conditions (Table 1). The most common chronic conditions among participants were circulatory system diseases (71.2\%), followed by endocrine and metabolic disorders (53.2\%), and mental 
Table 2 Therapy- and Patient-Related Factors of the Participants of the Study according to their Self-Reported Measure of Medication Adherence, $n=299$

\begin{tabular}{|c|c|c|c|c|c|c|}
\hline \multirow[t]{2}{*}{ Factors } & \multirow{2}{*}{$\begin{array}{l}\text { Total } n(\%) \\
n=299\end{array}$} & \multirow{2}{*}{$\begin{array}{l}\text { Adherent } \mathrm{n}(\%) \\
n=166\end{array}$} & \multirow{2}{*}{$\begin{array}{l}\text { Poor Adherent } \mathrm{n}(\%) \\
n=133\end{array}$} & \multicolumn{3}{|c|}{ Bivariate Analyses } \\
\hline & & & & Crude OR & $95 \% \mathrm{Cl}$ & $p$-value \\
\hline \multicolumn{7}{|l|}{ Therapy-Related } \\
\hline Number of prescriptions, mean $\pm S D$ & $3.90 \pm 2.2$ & $3.94 \pm 2.2$ & $3.85 \pm 2.3$ & 1.02 & (0.92 to 1.13$)$ & 0.725 \\
\hline Number of pills, mean $\pm S D$ & $4.36 \pm 2.9$ & $4.26 \pm 2.9$ & $4.50 \pm 3.0$ & 0.97 & (0.90 to 1.05$)$ & 0.482 \\
\hline \multicolumn{7}{|l|}{ Medication through injections } \\
\hline Using injections & $33(11.0)$ & $18(10.8)$ & $15(11.3)$ & Ref. & Ref. & \\
\hline Not using injections & $266(89.0)$ & $148(89.2)$ & $118(88.7)$ & 1.05 & (0.51 to 2.16$)$ & 0.905 \\
\hline \multicolumn{7}{|l|}{ Therapy through inhalers } \\
\hline Using inhalers & $28(9.4)$ & $14(8.4)$ & $14(10.5)$ & Ref. & Ref. & \\
\hline Not using inhalers & $271(90.6)$ & $152(91.6)$ & $119(89.5)$ & 1.28 & (0.59 to 2.78$)$ & 0.538 \\
\hline \multicolumn{7}{|l|}{ Interfering with Activities of Daily Living } \\
\hline Interfering & $27(9.03)$ & $10(6.0)$ & $17(12.8)$ & Ref. & Ref. & \\
\hline Not-interfering & $272(91.0)$ & $156(94.0)$ & $116(87.2)$ & 2.29 & (1.01 to 5.18$)$ & 0.047 \\
\hline \multicolumn{7}{|l|}{ Patient-Related } \\
\hline \multicolumn{7}{|l|}{ Functional Independency of Daily Living Activities } \\
\hline Independent & $234(78.3)$ & $127(76.5)$ & $107(80.5)$ & Ref. & Ref. & \\
\hline Slightly dependent & $49(16.4)$ & $29(17.5)$ & $20(15.0)$ & 1.22 & (0.65 to 2.28$)$ & 0.530 \\
\hline Moderately dependent & $16(5.4)$ & $10(6.0)$ & $6(4.5)$ & 1.40 & (049 to 3.99) & 0.524 \\
\hline Severely dependent & $0(0)$ & $0(0)$ & $0(0)$ & - & - & - \\
\hline Totally dependent & $0(0)$ & $0(0)$ & $0(0)$ & - & - & - \\
\hline \multicolumn{7}{|l|}{ Medication Dosing Reminders } \\
\hline Not using any reminder & $85(28.4)$ & $27(16.3)$ & $58(43.6)$ & Ref. & Ref. & \\
\hline Use of alarms/phones/pillboxes & $80(26.8)$ & $50(30.1)$ & $30(22.6)$ & 3.58 & (1.88 to 6.81$)$ & $<0.001$ \\
\hline Association of medication with daily routines & $134(44.8)$ & $89(53.6)$ & $45(33.8)$ & 4.25 & (2.38 to 7.59 ) & $<0.001$ \\
\hline \multicolumn{7}{|l|}{ Patient's Knowledge about Medication Regimen } \\
\hline Not having an adequate knowledge & $173(57.9)$ & $75(45.2)$ & $98(73.7)$ & Ref. & Ref. & \\
\hline Having an adequate knowledge & $126(42.1)$ & $91(54.8)$ & $35(26.3)$ & 3.40 & (2.08 to 5.56$)$ & $<0.001$ \\
\hline \multicolumn{7}{|l|}{ Perceived Overmedication in the Treatment } \\
\hline Perception of overmedication & $26(8.7)$ & $12(7.2)$ & $14(10.5)$ & Ref. & Ref. & \\
\hline Not-perception of overmedication & $273(91.3)$ & $154(92.8)$ & $119(89.5)$ & 1.51 & (0.67 to 3.39$)$ & 0.317 \\
\hline \multicolumn{7}{|l|}{ Self-Perceived Quality of Life } \\
\hline Not having good quality of life & $153(51.2)$ & $76(45.8)$ & 77 (57.9) & Ref. & Ref. & \\
\hline Having good quality of life & $146(48.8)$ & $90(54.2)$ & $56(42.1)$ & 1.63 & (1.03 to 2.58$)$ & 0.038 \\
\hline
\end{tabular}

Abbreviations: $C l$, confidence interval; $O R$, odds ratio; $S D$, standard deviation; Ref., reference Bold values are statistically significant at $p$-values $\leq 0.05$

and nervous system diseases (37.8\%) (Additional file 1: Table S1).

\section{Adherence to treatment}

The proportion of adherent patients to treatment according to the Morisky-Green-Levine questionnaire was $55.5 \%$. Medium and low adherence rates were $39.8 \%$ and $4.7 \%$ respectively and comprised the "poor-adherent group" (44.5\%). The likely causes for non-adherence among the poor-adherent group were occasionally forgetting to take medications (79.0\%), being careless at times about taking medications (29.3\%), discontinuing medications when feeling better $(21.1 \%)$, and discontinuing medications when feeling worse $(24.1 \%)$ (Additional file 1: Table S2).

\section{Factors associated with adherence}

Bivariate logistic analyses revealed several factors associated with medication adherence in all the WHO 
Table 3 Multivariable Logistic Regression Models between Factors in the WHO's Domains and Medication Adherence as Measured by the Four-Item Morisky-Green-Levine Self-Reported Questionnaire, $n=299$

\begin{tabular}{|c|c|c|c|}
\hline \multirow[b]{2}{*}{ Factors } & \multicolumn{3}{|c|}{ Multivariate Logistic Regression } \\
\hline & Adjusted OR & $95 \% \mathrm{Cl}$ & $p$-value \\
\hline \multicolumn{4}{|l|}{ Social and Economic } \\
\hline Age (per 10-year increment) & 1.31 & $(1.01-1.70)$ & 0.039 \\
\hline \multicolumn{4}{|l|}{ Immigration Status } \\
\hline Born in Spain & Ref. & Ref. & \\
\hline Immigrated to Spain & 0.64 & (0.25 to 1.65$)$ & 0.352 \\
\hline \multicolumn{4}{|l|}{ Living Status } \\
\hline Living alone & Ref. & Ref. & \\
\hline Living with someone & 1.81 & (0.89 to 3.68$)$ & 0.099 \\
\hline \multicolumn{4}{|l|}{ Healthcare Team and System-Related } \\
\hline Number of Pharmacies Used for Refills & 0.65 & (0.47 to 0.90$)$ & 0.008 \\
\hline \multicolumn{4}{|l|}{ Treatment Information Received } \\
\hline Not receiving complete information & Ref. & Ref. & \\
\hline Receiving complete information & 3.89 & (2.09 to 7.21$)$ & $<0.001$ \\
\hline \multicolumn{4}{|l|}{ Condition-Related Factors } \\
\hline Number of Chronic Conditions & 1.31 & (0.99 to 1.73$)$ & 0.061 \\
\hline \multicolumn{4}{|l|}{ Adjusted Morbidity Group } \\
\hline AMG1 & Ref. & Ref. & \\
\hline AMG2 & 0.68 & (0.28 to 1.69$)$ & 0.410 \\
\hline AMG3 & 0.84 & (0.28 to 2.79$)$ & 0.836 \\
\hline \multicolumn{4}{|l|}{ Therapy-Related } \\
\hline \multicolumn{4}{|l|}{ Interfering with Activities of Daily Living } \\
\hline Interfering & Ref. & Ref. & \\
\hline Not-interfering & 1.52 & (0.53 to 4.34$)$ & 0.432 \\
\hline \multicolumn{4}{|l|}{ Patient-Related } \\
\hline \multicolumn{4}{|l|}{ Medication Dosing Reminders } \\
\hline Not using any reminder & Ref. & Ref. & \\
\hline Use of alarms/phones/pillboxes & 1.56 & (0.69 to 3.52$)$ & 0.281 \\
\hline Association of medication with daily routines & 1.55 & (0.74 to 3.28$)$ & 0.244 \\
\hline \multicolumn{4}{|l|}{ Patient's Knowledge about Medication Regimen } \\
\hline Not having an adequate knowledge & Ref. & Ref. & \\
\hline Having an adequate knowledge & 4.17 & (2.23 to 7.80$)$ & $<0.001$ \\
\hline \multicolumn{4}{|l|}{ Self-Perceived Quality of Life } \\
\hline Not having good quality of life & Ref. & Ref. & \\
\hline Having good quality of life & 2.17 & (1.18 to 4.02 ) & 0.013 \\
\hline
\end{tabular}

Abbreviations: $\mathrm{Cl}$, confidence interval; $\mathrm{OR}$, odds ratio; Ref., reference

Bold values are statistically significant at $p$-values $\leq 0.05$

dimensions (Table 1 and Table 2). Variables significantly associated with adherence ( $p$-value $\leq 0.05)$ were included in the multivariable logistic regression analyses. After multivariable adjustment, five factors were independently associated with adherence (Table 3). Participants who were older (adjusted odds ratio 1.31 per 10-year increment, 95\% confidence interval [CI] 1.01-
1.70), refilled prescriptions in lower number of pharmacies $(0.65,95 \%$ CI $0.47-0.90)$, received complete information about treatment (3.89, 95\% CI 2.09-7.21), had adequate knowledge about medication regimen (4.17, 95\% CI 2.23-7.80), and self-perceived of having good quality of life $(2.17,95 \%$ CI $1.18-4.02)$ were more likely to adhere to treatment schedule regimens (Fig. 1). 


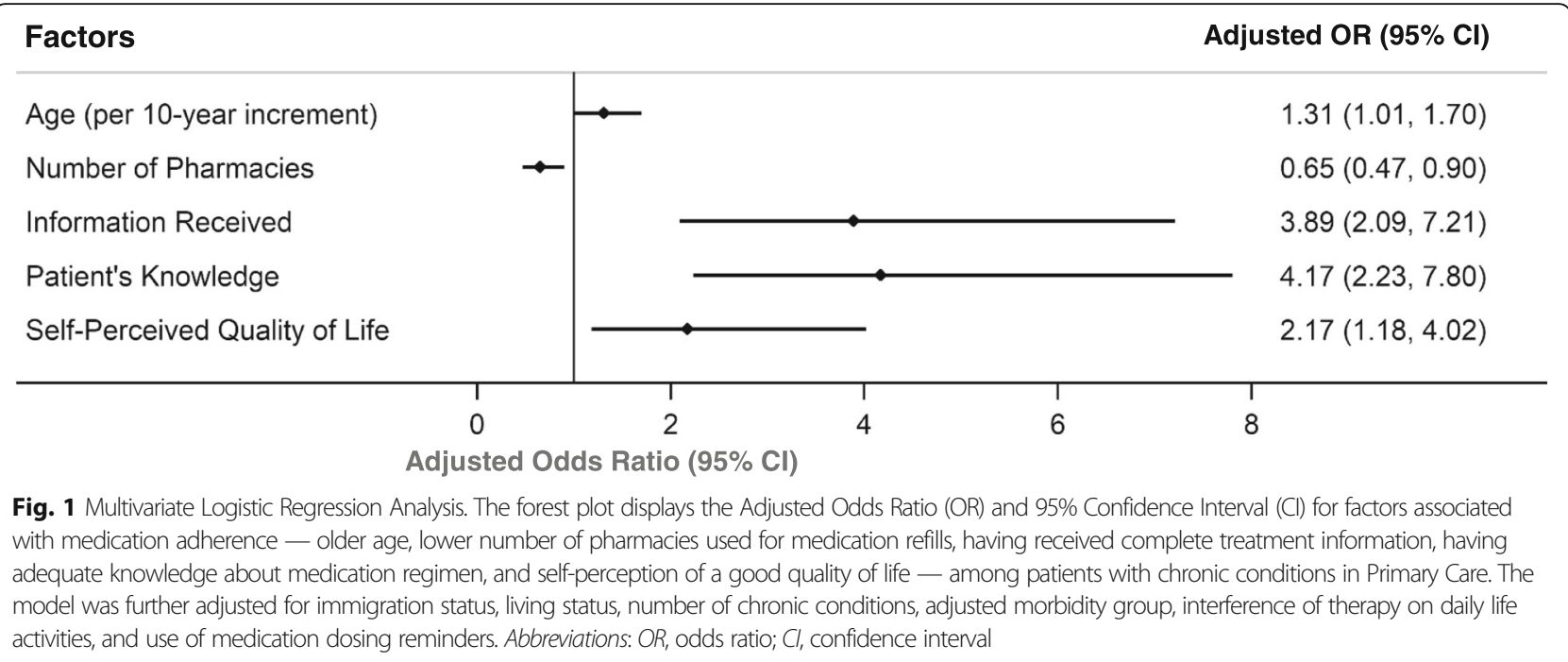

\section{Sensitivity analyses}

To test the robustness of our results and the validity and reliability of the methods used for assessing adherence, we conducted multiple linear regression analysis using patient's overall medication score (0-4 score) as continuous dependent variable. Age, the number of pharmacies used to refill prescriptions, treatment information received, and knowledge about treatment were consistently associated with medication adherence (Table 4).

\section{Discussion}

To our knowledge, this is the first attempt to determine factors associated with adherence under the WHO multidimensional framework in patients with chronic conditions in primary care settings in Spain. The results showed that slightly more than half of the subjects of the cohort remained adherent to long-term therapies for chronic conditions, which points to substantial room for improvement at the primary-care level. Forgetfulness was the main likely cause of non-adherence among the poor adherence group. After adjustment for several variables, we found age, the number of pharmacies used for medication refills, the treatment information received, patients' knowledge about medication regimen, and selfperceived quality of life as independent factors of adherence.

The adherence rate found in our study was consistent with the WHO report that states "in developed countries, adherence among patients suffering chronic diseases averages only 50\%" [9]. Compared with previous international studies, the adherence rate assessed in this study was similar to the $53 \%$ found in Chinese primarycare centers [31], the $48 \%$ reported in uninsured American patients who attended community health centers [32], but slightly higher than the 39\% observed in Italian outpatient adults [24]. At the national level, our findings are consistent with prior research in Spain performed in chronic patients [33], but significantly different in terms of the adherence rate of $18 \%$ reported in tertiary-care settings [23].

Patient's knowledge about medication regimen provided the strongest predictor of adherence. A large proportion of participants found it difficult to explain the amount, number, and frequency of doses associated with their medications, negatively affecting their adherence. For patients with chronic conditions, understanding of their own diseases and the complex regimens may represent a challenge [34]. For example, Friis et al. [35] found that individuals with long-term diseases had more difficulties in comprehending provider health information. Similarly, Fredericksen et al. [36] and Kvarnström et al. [37] reported frequent misconceptions and lack of understanding of the purpose of medications among the chronically ill.

Our analyses also proved that treatment information was an important predictor of adherence. Clear, unbiased, and proper information improves patients' understanding of their treatment, increases awareness of benefits and risks of medication, and sets realistic expectations, which improves adherence [38]. Nonetheless, patients frequently receive little information about treatment during clinical consultations [39] and have needs and concerns that are not addressed [40].

General practitioners (GPs), responsible for much of the prescribing medication and counseling for chronic conditions [18-20], have reported time pressure as a frequent barrier for informing and educating patients in primary care settings [38]. Moreover, physicians have acquired strategies to manage consultation times by interrupting patients before giving them the opportunity to explain their concerns completely [41]. Such circumstances may lead patients to experience greater 
Table 4 Multiple Linear Regression Analysis of Factors of Adherence using the Morisky-Green-Levine's Scale Score, $n=299$

\begin{tabular}{|c|c|c|c|c|}
\hline \multirow[b]{2}{*}{ Factors } & \multicolumn{4}{|c|}{ Multivariate Linear Regression Model } \\
\hline & Correlation Coeficient & SE & $95 \% \mathrm{Cl}$ & $p$-value \\
\hline \multicolumn{5}{|l|}{ Social and Economic } \\
\hline Age (per 10-year increment) & -0.15 & 0.04 & $(-0.23$ to -0.07$)$ & 0.001 \\
\hline \multicolumn{5}{|l|}{ Immigration Status } \\
\hline Born in Spain & Ref. & & Ref. & \\
\hline Immigrated to Spain & 0.27 & 0.15 & $(-0.02$ to 0.56$)$ & 0.070 \\
\hline \multicolumn{5}{|l|}{ Living Status } \\
\hline Living alone & Ref. & & Ref. & \\
\hline Living with someone & -0.18 & 0.11 & $(-0.40$ to 0.04$)$ & 0.107 \\
\hline \multicolumn{5}{|l|}{ Healthcare Team and System-Related } \\
\hline Number of Pharmacies Used for Refills & 0.14 & 0.05 & (0.04 to 0.24$)$ & 0.005 \\
\hline${ }^{1}$ Treatment Information Received & -0.20 & 0.05 & $(-0.30$ to -0.10$)$ & $<0.001$ \\
\hline \multicolumn{5}{|l|}{ Condition-Related Factors } \\
\hline Number of Chronic Conditions & -0.07 & 0.04 & $(-0.16$ to 0.01$)$ & 0.077 \\
\hline \multicolumn{5}{|l|}{ Adjusted Morbidity Group } \\
\hline AMG1 & Ref. & & Ref. & \\
\hline AMG2 & 0.11 & 0.14 & $(-0.16$ to 0.39$)$ & 0.427 \\
\hline AMG3 & 0.15 & 0.18 & $(-0.21$ to 0.51$)$ & 0.412 \\
\hline \multicolumn{5}{|l|}{ Therapy-Related } \\
\hline \multicolumn{5}{|l|}{ Interfering with Activities of Daily Living } \\
\hline Interfering & Ref. & & Ref. & \\
\hline Not-interfering & 0.06 & 0.16 & $(-0.27$ to 0.38$)$ & 0.736 \\
\hline \multicolumn{5}{|l|}{ Patient-Related } \\
\hline \multicolumn{5}{|l|}{ Medication Dosing Reminders } \\
\hline Not using any reminder & Ref. & & Ref. & \\
\hline Use of alarms/phones/pillboxes & 0.02 & 0.14 & $(-0.25$ to 0.29$)$ & 0.878 \\
\hline Association of medication with daily routines & -0.17 & 0.13 & (-0.42 to 0.09$)$ & 0.200 \\
\hline${ }^{1}$ Knowledge about Medication Regimen & -0.17 & 0.05 & $(-0.26$ to -0.08$)$ & $<0.001$ \\
\hline${ }^{1}$ Self-Perceived Quality of Life & -0.05 & 0.04 & $(-0.14$ to 0.04$)$ & 0.264 \\
\hline
\end{tabular}

Abbreviations: $S E$, standard error; $C l$, confidence interval; Ref., reference

Bold values are statistically significant at $p$-values $\leq 0.05$

${ }^{1}$ Introduced as Likert scale score (1-5)

frustration, and to wish that their provider had more time to spend talking to them addressing their concerns [42].

To improve patients' education and to tackle the nonadherence concern, GPs have enlisted more cooperation from other allied health professionals such as nurses and pharmacists [37]. They can play an important role in patients' education and counseling. Nurses can educate patients by providing information on diseases and patients' diagnosis [43, 44]. Additionally, they can promote selfmanagement of chronic conditions and support medication adherence. Similarly, pharmacists may enrich patient's education by providing information regarding medication such as proper use of drugs, potential side effects and interactions, dosing schedules, and healthy lifestyles [43, 44]. Likewise, pharmacists have enhanced medication adherence by using motivational interviewing skills, reviewing patients' regimens, supervising treatment efficacy and security, and discussing the management of missed doses. [45]. These factors suggest the importance of strengthening collaboration between GPs, nurses, and pharmacists to improve patients' care. $\mathrm{Pa}$ tients also believe that interprofessional collaborations are needed to provide the best care possible [46].

We found that, as the number of pharmacies used for refilling prescriptions increased, treatment adherence decreased. This is consistent with previous studies that have found patients who made more visits to more pharmacies and those with less refill consolidation were substantially less adherent to their therapies [47, 48]. This 
finding underlies the importance of the role of pharmacist in the context of medication adherence.

The use of a single pharmacy allows patients to have a long-term relationship with pharmacists that fosters pharmacist-patient communication and counseling. Use of only one pharmacy to refill prescriptions also facilitates the pharmacist's ability to track patients' medication, improves patients' follow up, and establishes a consistent medication record. Having a pharmacy-based computer system connecting all pharmacies may be one possible approach; however, it may lead patient to confusion in managing medications and hinder communication between patient, physicians, nurses, and pharmacists. Moreover, pharmacists have reported a lack of confidence in having a complete idea of medication lists when patients use multiple pharmacies and may be less likely to optimize drug utilization and safety [49]. Use of a single pharmacy, commonly called a "pharmacy home", has been proposed as a helpful way to foster patient-pharmacist communication and maintain a better control of medication $[47,48,50]$. However, a pharmacy home may be impractical for many patients and increase out of pocket costs [51]. As such, integrating pharmacists into primary care, as previously discussed, may represent the most evidence-based and feasible approach. Such an example occurs in North Carolina, where clinical pharmacist practitioners are integrated into primary care in team-based models of care having positive impact on clinical and cost outcomes [52, 53].

Self-perception of a good quality of life and older age were also associated with adherence. Nonetheless, a lack of consensus exists about their precise effect. While some studies corroborate our findings suggesting a relationship between quality of life and adherence attributed to the influence of some psycho-social characteristics related to the ability of manage chronic diseases [54], others have not found such association [55]. Similarly, the effect of age has been inconsistent across adherence studies. An increase in age is generally associated with a greater adherence as younger people may perceive less severity of disease. This association continues until the onset of some aging processes, such as cognitive impairments, which usually occurs around the 70 years of age, in which adherence starts to decline [56].

Our results should be interpreted in light of several limitations. Self-reported questionnaires use for measuring adherence may be susceptible to recall bias and may underestimate the true extent of non-adherence [57]. Nonetheless, the Morisky-Green-Levine questionnaire has yielded fair psychometric properties (sensitivity= 0.81 , specificity $=0.44$ ), and provided a useful tool to evaluate medication adherence in numerous chronic disease studies. Furthermore, patients may want to please their healthcare providers with their responses and may incur in social desirability bias. To minimize this problem, the interviewer was not affiliated with the study sites and had no contact with participants prior to the interview. Another limitation reflects the nature of the study itself. The cross-sectional design may limit evaluation of cause-effect relationships. Longitudinal studies should explore the temporal validity of the associations found here. Lastly, the reference proportion of participants not adhering to prescribed medications proposed to calculate the sample size of the study differs from the final findings, which may have somewhat underpowered our results. Nonetheless, study's strengths rest in the assessment of overall adherence in patients with chronic diseases rather than adherence to one single condition or particular drug therapy. We have considered a number of common chronic conditions and evaluated several factors using the WHO conceptual framework. Furthermore, since multimorbidity has become the rule rather the exception in primary care settings [20], our research provides a more realistic and accurate assessment of the non-adherence problem.

\section{Conclusions}

Adherence to long-term treatments for chronic conditions remains a challenging issue in primary care. A low proportion of patients followed the recommendations from healthcare providers which underlines the need of reinforcing medication adherence in primary care. Our results should help to design new interventions aimed to enhance adherence. Considerable attention should be given to the multidimensional factors potentially amenable to intervention found in this study such as patient's knowledge and information. Health professionals should emphasize on meeting patients' information needs and reinforcing their education on treatment and diseases. Our results also provide firm evidence of the positive impact of pharmacists on patients' adherence when having a consolidated relationship. Due to current and future challenges in primary care, future research is needed to evaluate the extent of integrating pharmacists into new team-based models of primary care.

\section{Additional file}

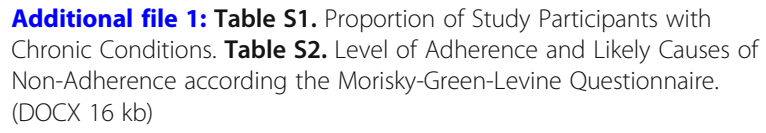

Additional file 1: Table S1. Proportion of Study Participants with Chronic Conditions. Table S2. Level of Adherence and Likely Causes of Non-Adherence according the Morisky-Green-Levine Questionnaire. (DOCX $16 \mathrm{~kb}$ )

\section{Abbreviations}

AMG: Adjusted morbidity group; Cl: Confidence interval; GPs: General practitioners; OR: Odds ratio; Ref: Reference; SD: Standard deviation; SE: Standard error; SNHS: Spanish National Health System; WHO: World Health Organization 


\section{Acknowledgments}

We would like to thank all the primary care physicians and the staff of the centers for their cooperation with the study. Special thanks to Juan GasteluIturri Bilbao, Francisco Javier Iglesias Gomez, and Valentín del Villar Sordo to facilitate the coordination of this study. Many thanks to all the patients for their willingness to participate.

\section{Authors' contributions}

C. F-L., the primary author, was involved in design of the study, conducted the research, performed the data analysis and interpretation, and drafted the manuscript. J. G-G. assisted in data analysis and drafting the manuscript and provided critical edits to the manuscript. D. A. was involved with study conception, study oversight, and provided critical edits to the manuscript. D. F-L. was involved with data interpretation and provided critical edits to the manuscript. J.M-A. assisted in data analyses and interpretation of the data. A.C-G., was involved in the conception and design of the design. F.M.R. was involved in the conception of the study and data acquisition. A.C. assisted in interpretation of the data and provided critical edits to the manuscript. J. MC. was the senior author involved with study conception and design, study oversight, and provided critical edits to the manuscript. All authors have approved the final version of the manuscript.

\section{Funding}

This research did not receive any specific grant from funding agencies in the public, commercial, or not-for-profit sectors.

\section{Availability of data and materials}

Data will be available upon reasonable request from the corresponding author.

\section{Ethics approval and consent to participate}

Participation in the study was entirely voluntary. All participants provided written informed consent to take part in the study. Before patients consented to participate in the interview, all the subjects received a detailed both written and oral information about the study. Patients were also informed that they could withdraw from the study at any time without penalty. Patients' information was coded and stored safely, and only the researcher had access to it. This study was conducted in accordance with the Declaration of Helsinki and was approved by the Ethics Committee of the Hospital Complex of Soria.

\section{Consent for publication}

Written consent was received from all participants to publicly share the results of the study.

\section{Competing interests}

The authors declare that they have no competing interests.

\section{Author details}

'Department of Biomedical and Diagnostic Sciences, School of Medicine, University of Salamanca, Calle Alfonso X el Sabio s/n, 37007 Salamanca, Spain. ${ }^{2}$ Department of Preventive Medicine and Public Health, School of Medicine, IDISNA, University of Navarra, Pamplona, Spain. ${ }^{3}$ Department of Sociology, Pablo de Olavide University, Seville, Spain. ${ }^{4}$ Dual Enrollment Program, Point University-Savannah Campus, Savannah, GA, USA.

${ }^{5}$ Department of Cell Biology, Histology and Pharmacology, University of Valladolid, Soria, Spain. ${ }^{6}$ Department of Biochemistry, Molecular Biology and Physiology, Faculty of Physical Therapy, University of Valladolid, Soria, Spain. ${ }^{7}$ Department of Anatomy and Radiology, University of Valladolid, Soria, Spain. ${ }^{8}$ Castile and Leon Healthcare Services, Valladolid, Spain.

Received: 17 April 2019 Accepted: 30 August 2019

Published online: 14 September 2019

\section{References}

1. Christensen K, Doblhammer G, Rau R, Vaupel JW. Ageing populations: the challenges ahead. Lancet. 2009;374:1196-208 doi.org/10.1016/S0140-6736 (09)61460-4.

2. Bloom DE, Cafiero E, Jané-Llopis E. Abrahams-Gessel S. Fathima S, et al. The global economic burden of noncommunicable diseases. Program on the Global Demography of Aging: Bloom LR; 2012.
3. Bernell S, Howard SW. Use Your Words Carefully: What Is a Chronic Disease. Front Public Health. 2016;4:159 doi.org/10.3389/fpubh.2016.00159.

4. van der Heide I, Snoeijs S, Melchiorre MG, Quattrini S, Boerma W, Schellevis $\mathrm{F}$, et al. Innovating care for people with multiple chronic conditions in Europe. Brussels: ICARE4EU; 2015.

5. Boyd CM, Martin Fortin MD. Future of multimorbidity research: how should understanding of multimorbidity inform health system design? Public Health Rev. 2010;32:1.

6. Centers for Disease Control and Prevention, National Center for Chronic Disease Prevention and Health Promotion (NCCDPHP). Chronic Diseases in America. 2019. https://www.cdc.gov/chronicdisease ,Accessed 17 Jan 2019.

7. Lorig KR, Ritter P, Stewart AL, Sobel DS, Brown BW Jr, Bandura A, et al. Chronic disease self-management program: 2-year health status and health care utilization outcomes. Med Care. 2001;39:1217-23.

8. Bodenheimer T, Lorig K, Holman H, Grumbach K. Patient self-management of chronic disease in primary care. Jama. 2002;288:2469-75. https://doi.org/ 10.1001/jama.288.19.2469.

9. Sabaté E. Adherence to long-term therapies: evidence for action. Switzerland: World Health Organization; 2003.

10. Molimard M, Le Gros V. Impact of patient-related factors on asthma control. J Asthma. 2008:45:109-13. https://doi.org/10.1080/02770900701815727.

11. Venditti EM, Tan K, Chang N, Laffel L, McGinley G, Miranda N, et al. Barriers and strategies for oral medication adherence among children and adolescents with Type 2 diabetes. Diabetes Res Clin Pract. 2018;139:24-31. https://doi.org/10.1016/j.diabres.2018.02.001.

12. Kripalani S, Gatti ME, Jacobson TA. Association of age, health literacy, and medication management strategies with cardiovascular medication adherence. Patient Educ Couns. 2010;81:177-81. https://doi.org/10.1016/J. PEC.2010.04.030.

13. Bidwal M, Lor K, Yu J, Ip E. Evaluation of asthma medication adherence rates and strategies to improve adherence in the underserved population at a Federally Qualified Health Center. Res Soc Adm Pharm. 2017;13:759-66. https://doi.org/10.1177/2040622317714966.

14. Casebeer L, Huber C, Bennett N, Shillman R, Abdolrasulnia M, Salinas GD, et al. Improving the physician-patient cardiovascular risk dialogue to improve statin adherence. BMC Fam Pract. 2009;10:48. https://doi.org/10. 1186/1471-2296-10-48.

15. Palladino R, Tayu Lee J, Ashworth M, Triassi M, Millett C. Associations between multimorbidity, healthcare utilisation and health status: evidence from 16 European countries. Age Ageing. 2016;45:431-5. https://doi.org/10. 1093/ageing/afw044

16. Prados-Torres A, Poblador-Plou B, Calderón-Larrañaga A, Gimeno-Feliu LA, González-Rubio F, Poncel-Falcó A, et al. Multimorbidity Patterns in Primary Care: Interactions among Chronic Diseases Using Factor Analysis. PLoS One. 2012;7:e32190. https://doi.org/10.1371/journal.pone.0032190.

17. Foreman KJ, Marquez N, Dolgert A, Fukutaki K, Fullman N, McGaughey M, et al. Forecasting life expectancy, years of life lost, and all-cause and causespecific mortality for 250 causes of death: reference and alternative scenarios for 2016-40 for 195 countries and territories. Lancet. 2018;392: 2052-90. https://doi.org/10.1016/S0140-6736(18)31694-5.

18. Van Oostrom SH, Picavet HSJ, De Bruin SR, Stirbu I, Korevaar JC, Schellevis $\mathrm{FG}$, et al. Multimorbidity of chronic diseases and health care utilization in general practice. BMC Fam Pract. 2014;15:61. https://doi.org/10.1186/14712296-15-61.

19. Glynn LG, Valderas JM, Healy P, Burke E, Newell J, Gillespie P, et al. The prevalence of multimorbidity in primary care and its effect on health care utilization and cost. Fam Pract. 2011;28:516-23. https://doi.org/10.1093/fampra/cmr013.

20. Fortin M, Lapointe L, Hudon C, Vanasse A. Multimorbidity is common to family practice: is it commonly researched? Can Fam Physician. 2005;51:244-5.

21. Prado JC, Mion D. Adherence to Medication: The Importance of Research in Primary Care. Am J Hypertens. 2010;23:109-9. https://doi.org/10.1038/ajh.2009.205.

22. Ministry of Health and Social Policy. Health Information Institute. National Health System of Spain. Madrid; 2012. http://www.msps.es/en/organizacion/ sns/libroSNS.htm ,Accessed 29 Jun 2019

23. Jansa M, Hernandez C, Vidal M, Nunez M, Bertran MJ, Sanz S, et al. Multidimensional analysis of treatment adherence in patients with multiple chronic conditions. A cross-sectional study in a tertiary hospital. Patient Educ Couns. 2010;81:161-8. https://doi.org/10.1016/j.pec.2009.12.012.

24. Napolitano F, Napolitano P, Angelillo IF, Group CW. Medication adherence among patients with chronic conditions in Italy. Eur J Pub Health. 2015;26: 48-52. https://doi.org/10.1093/eurpub/ckv147. 
25. Val Jiménez A, Amorós Ballestero G, Martínez Visa P, Fernández Ferré ML, León SM. Descriptive study of patient compliance in pharmacologic antihypertensive treatment and validation of the Morisky and Green test. Aten Primaria. 1992;10:767-70.

26. Morisky DE, Green LW, Levine DM. Concurrent and predictive validity of a self-reported measure of medication adherence. Med Care. 1986;24:67-74.

27. Hughes JS, Averill RF, Eisenhandler J, Goldfield NI, Muldoon J, Neff JM, et al. Clinical Risk Groups (CRGs): a classification system for risk-adjusted capitation-based payment and health care management. Med Care. 2004; 42:81-90. https://doi.org/10.1097/01.mlr.0000102367.93252.70.

28. Gerencia Regional de Castilla y León. Estrategia de Atención al Paciente Crónico en Castilla y León [Integrated Healthcare Model for Chronic Patients in the Regional Health Services of Castile and Leon]. Valladolid: Junta de Castilla y León; 2015.

29. World Health Organization. Global recommendations on physical activity for health. World Health Organization. Geneva; 2010. http://apps.who.int/iris/ handle/10665/44399,Accessed 9 Sept 2018

30. Mahoney FI, Barthel DW. Functional evaluation: the Barthel index. Md State Med J. 1965;14:61-5.

31. Li YT, Wang HHX, Liu KQL, Lee GKY, Chan WM, Griffiths SM, et al. Medication Adherence and Blood Pressure Control Among Hypertensive Patients With Coexisting Long-Term Conditions in Primary Care Settings. Medicine (Baltimore). 2016;95:e3572. https://doi.org/10.1097/MD.0000000000003572.

32. Fernandez-Lazaro Cl, Adams DP, Fernandez-Lazaro D, Garcia-González JM, Caballero-Garcia A, Miron-Canelo JA. Medication adherence and barriers among low-income, uninsured patients with multiple chronic conditions. Res Social Adm Pharm. 2019;15:744-53. https://doi.org/10.1016/j.sapharm. 2018.09.006.

33. Pagès-Puigdemont $N$, Tuneu L, Masip M, Valls $P$, Puig T, Mangues MA. Determinants of medication adherence among chronic patients from an urban area: a cross-sectional study. Eur J Pub Health. 2019;29:419-24. https://doi.org/10.1093/eurpub/cky259.

34. Wens J, Vermeire E, Van Royen P, Sabbe B, Denekens J. GPs' perspectives of type 2 diabetes patients' adherence to treatment: A qualitative analysis of barriers and solutions. BMC Fam Pract. 2005;6:20. https://doi.org/10.1186/ 1471-2296-6-20.

35. Friis K, Lasgaard M, Osborne RH, Maindal HT. Gaps in understanding health and engagement with healthcare providers across common long-term conditions: a population survey of health literacy in 29473 Danish citizens. BMJ Open. 2016;6:e009627. https://doi.org/10.1136/bmjopen-2015-009627.

36. Fredericksen RJ, Gibbons L, Brown S, Edwards TC, Yang FM, Fitzsimmons E, et al. Medication understanding among patients living with multiple chronic conditions: Implications for patient-reported measures of adherence. Res Soc Adm Pharm. 2018;14:540-4. https://doi.org/10.1016/j. sapharm.2017.06.009.

37. Kvarnström K, Airaksinen M, Liira H. Barriers and facilitators to medication adherence: a qualitative study with general practitioners. BMJ Open. 2018;8: e015332. https://doi.org/10.1136/bmjopen-2016-015332.

38. Say RE, Thomson R. The importance of patient preferences in treatment decisions--challenges for doctors. BMJ. 2003;327:542-5. https://doi.org/10. 1136/bmj.327.7414.542.

39. Barry CA, Bradley CP, Britten N, Stevenson FA, Barber N. Patients' unvoiced agendas in general practice consultations: qualitative study. BMJ. 2000;320: 1246-50. https://doi.org/10.1136/bmj.320.7244.1246.

40. Barber N, Parsons J, Clifford S, Darracott R, Horne R. Patients' problems with new medication for chronic conditions. Qual Saf Health Care. 2004;13:172-5. https://doi.org/10.1136/qhc.13.3.172

41. Marvel MK, Epstein RM, Flowers K, Beckman HB. Soliciting the Patient's Agenda. JAMA. 1999;281:283. https://doi.org/10.1001/jama.281.3.283.

42. Smith ML, Bergeron CD, Adler CH, Patel A, Ahn S, Towne SD, et al. Factors associated with healthcare-related frustrations among adults with chronic conditions. Patient Educ Couns. 2017;100:1185-93. https://doi.org/10.1016/J. PEC.2016.12.033

43. Celio J, Ninane F, Bugnon O, Schneider MP. Pharmacist-nurse collaborations in medication adherence-enhancing interventions: A review. Patient Educ Couns. 2018;101:1175-92. https://doi.org/10.1016/J.PEC.2018.01.022.

44. Matthys $E$, Remmen $R$, Van Bogaert P. An overview of systematic reviews on the collaboration between physicians and nurses and the impact on patient outcomes: what can we learn in primary care? BMC Fam Pract. 2017;18:110. https://doi.org/10.1186/s12875-017-0698-x
45. Mino-León D, Reyes-Morales H, Flores-Hernández S. Effectiveness of involving pharmacists in the process of ambulatory health care to improve drug treatment adherence and disease control. J Eval Clin Pract. 2015;21: 7-12. https://doi.org/10.1111/jep.12207.

46. Kelly DV, Young S, Phillips L, Clark D. Patient attitudes regarding the role of the pharmacist and interest in expanded pharmacist services. Can Pharm J (Ott). 2014;147:239-47. https://doi.org/10.1177/1715163514535731.

47. Choudhry NK, Fischer MA, Avorn J, Liberman JN, Schneeweiss S, Pakes J, et al. The implications of therapeutic complexity on adherence to cardiovascular medications. Arch Intern Med. 2011;171:814-22. https://doi. org/10.1001/archinternmed.2010.495

48. Marcum ZA, Driessen J, Thorpe CT, Gellad WF, Donohue JM. Effect of multiple pharmacy use on medication adherence and drug-drug interactions in older adults with Medicare Part D. J Am Geriatr Soc. 2014;62: 244-52. https://doi.org/10.1111/jgs.12645.

49. Fleming $M$, Nemlekar $P$, Brown CM, Cantu R. Exploratory study of community pharmacists' perceptions about new or transferred prescription incentives. J Am Pharm Assoc. 2012;52:e53-8. https://doi.org/10.1331/ JAPHA.2012.11096.

50. Salanitro AH, Kripalani S. Prescription refill management and its effect on adherence. Arch Intern Med. 2011;171:822-3. https://doi.org/10.1001/ archinternmed.2010.481.

51. Zhang Y, Gellad WF, Zhou L, Lin Y-J, Lave JR. Access to and use of $\$ 4$ generic programs in Medicare. J Gen Intern Med. 2012;27:1251-7. Epub 2012 Feb 7. https://doi.org/10.1007/s11606-012-1993-9.

52. Scott MA, Heck JE, Wilson CG. The Integral Role of the Clinical Pharmacist Practitioner in Primary Care. N C Med J. 2017;78:181-5. https://doi.org/10. 18043/ncm.78.3.181.

53. Hawes EM, Misita C, Burkhart JI, McKnight L, Deyo ZM, Lee R-A, et al. Prescribing pharmacists in the ambulatory care setting: experience at the University of North Carolina Medical Center. Am J Heal Pharm. 2016;73: 1425-33. https://doi.org/10.2146/ajhp150771.

54. Holt EW, Muntner P, Joyce CJ, Webber L, Krousel-Wood MA. Health-related quality of life and antihypertensive medication adherence among older adults. Age Ageing. 2010;39:481-7. https://doi.org/10.1093/ageing/afq040.

55. Côté I, Farris K, Feeny D. Is adherence to drug treatment correlated with health-related quality of life? Qual Life Res. 2003;12:621-33. https://doi.org/ 10.1023/A:1025180524614.

56. Krueger KP, Berger BA, Felkey B. Medication adherence and persistence: a comprehensive review. Adv Ther. 22:313-56. https://doi.org/10.1007/ BF02850081.

57. Osterberg L, Blaschke T. Adherence to medication. N Engl J Med. 2005;353: 487-97. https://doi.org/10.1056/NEJMra050100.

\section{Publisher's Note}

Springer Nature remains neutral with regard to jurisdictional claims in published maps and institutional affiliations.

Ready to submit your research? Choose BMC and benefit from:

- fast, convenient online submission

- thorough peer review by experienced researchers in your field

- rapid publication on acceptance

- support for research data, including large and complex data types

- gold Open Access which fosters wider collaboration and increased citations

- maximum visibility for your research: over $100 \mathrm{M}$ website views per year

At BMC, research is always in progress.

Learn more biomedcentral.com/submissions 